\title{
Prenatal diagnosis of Norrie disease after whole exome sequencing of an affected proband during an ongoing pregnancy: a case report
}

Andrey V. Marakhonov ${ }^{1 *}$ D, Irina A. Mishina', Vitaly V. Kadyshev', Svetlana A. Repina', Maria F. Shurygina², Olga A. Shchagina', Natalya N. Vasserman', Tatyana A. Vasilyeva', Sergey I. Kutsev ${ }^{1}$ and Rena A. Zinchenko ${ }^{1,3}$

From 11th International Young Scientists School "Systems Biology and Bioinformatics" - SBB-2019

\begin{abstract}
Background: Hereditary ophthalmic pathology is a genetically heterogeneous group of diseases that occur either as an isolated eye disorder or as a symptom of hereditary syndromes (chromosomal or monogenic). Thus, a diagnostic search in some cases of ophthalmic pathology can be time- and cost-consuming. The most challenging situation can arise when prenatal diagnosis is needed during an ongoing pregnancy.

Case presentation: A family was referred to the Research Centre for Medical Genetics (RCMG) for childbirth risk prognosis at 7-8 week of gestation because a previous child, a six-year-old boy, has congenital aniridia, glaucoma, retinal detachment, severe psychomotor delay, and lack of speech and has had several ophthalmic surgeries. The affected child had been previously tested for PAX6 mutations and 11p13 copy number variations, which revealed no changes. Considering the lack of pathogenic changes and precise diagnosis for the affected boy, NGS sequencing of clinically relevant genes was performed for the ongoing pregnancy; it revealed a novel hemizygous substitution NM_000266.3(NDP):c.385G > T, p.(Glu129*), in the NDP gene, which is associated with Norrie disease (OMIM \#310600). Subsequent Sanger validation of the affected boy and his mother confirmed the identified substitution inherited in X-linked recessive mode. Amniotic fluid testing revealed the fetus was hemizygous for the variant and lead to the decision of the family to interrupt the pregnancy. Complications which developed during the termination of pregnancy required hysterectomy due to medical necessity.

(Continued on next page)
\end{abstract}

\footnotetext{
*Correspondence: marakhonov@generesearch.ru

'Laboratory of Genetic Epidemiology, Research Centre for Medical Genetics, Moscow, Russian Federation
}

Full list of author information is available at the end of the article

(C) The Author(s). 2020 Open Access This article is licensed under a Creative Commons Attribution 4.0 International License, which permits use, sharing, adaptation, distribution and reproduction in any medium or format, as long as you give appropriate credit to the original author(s) and the source, provide a link to the Creative Commons licence, and indicate if changes were made. The images or other third party material in this article are included in the article's Creative Commons licence, unless indicated otherwise in a credit line to the material. If material is not included in the article's Creative Commons licence and your intended use is not permitted by statutory regulation or exceeds the permitted use, you will need to obtain permission directly from the copyright holder. To view a copy of this licence, visit http://creativecommons.org/licenses/by/4.0/ The Creative Commons Public Domain Dedication waiver (http://creativecommons.org/publicdomain/zero/1.0/) applies to the data made available in this article, unless otherwise stated in a credit line to the data. 
(Continued from previous page)

Conclusions: Clinical polymorphism of hereditary ophthalmic pathology can severely complicate establishment of an exact diagnosis and make it time- and cost-consuming. NGS appears to be the method-of-choice in complicated cases, and this could substantially hasten the establishment of a diagnosis and genetic risk estimation.

Keywords: Hereditary eye pathology, Clinical heterogeneity, NGS, NDP, Norrie disease

\section{Background}

Hereditary eye pathology is a genetically heterogeneous group of diseases that occur either as an isolated ocular disorder or as a symptom of syndromes (both chromosomal and monogenic). We present here the results of DNA diagnosis in a patient with complex ocular phenotype associated with severe systemic involvement using next-generation sequencing (NGS), not only to perform differential diagnosis but also to determine if such a complex clinical picture has a single etiology or is a result of an interaction of factors that could have both hereditary and environmental origin. The case is much more complicated because the proband's mother had an ongoing pregnancy, thus the DNA diagnosis was performed with urgent need for genetic risk estimation as well as subsequent prenatal diagnosis.

\section{Case presentation}

A family referred to the Research Centre for Medical Genetics (RCMG) for risk-affected childbirth prognosis at 7-8 week of gestation because a previous child, a sixyear-old boy, has congenital glaucoma, bilateral retinal detachment, and severe psychomotor delay and has had several ophthalmic surgeries (Fig. 1).

For the first time the proband (a full-term newborn) was examined by an ophthalmologist at the age of 4 months. Clinical presentation included roving eye movements and abnormal gaze behavior, but he had positive light perception and toy tracking. Intraocular pressure was 21 and $17 \mathrm{mmHg}$ (OD and OS, respectively). B-scan ultrasonography revealed a total funnel retinal detachment, iris aplasia in both eyes, an anterior chamber of

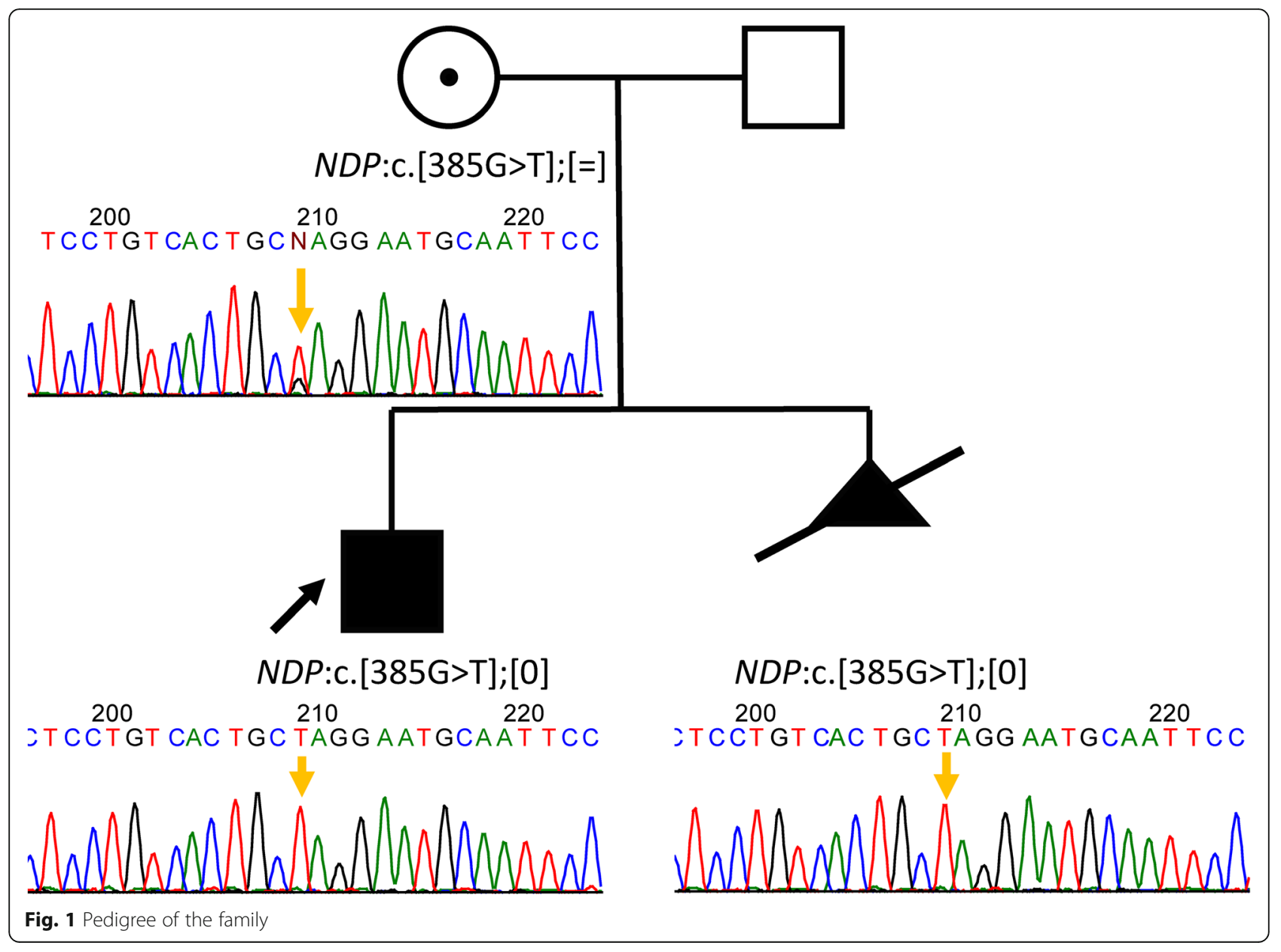


normal depth with an open angle, and undifferentiated trabecular meshwork, right eye lens opacity in all layers, bilateral vitreous fibrosis, and numerous fibrotic transocular folds behind the lenses. The proband was diagnosed as having the consequences of intrauterine uveitis, total retinal detachment, and secondary decompensated glaucoma. He later underwent several surgeries: 2 lensectomies, 4 vitrectomies, retinotomy, and subretinal aqueous drainage. No genetic test was performed at that time. The family never sought genetic counseling.

By the date when the family was referred for genetic counseling, the boy was blind in both eyes, had total bilateral retinal detachment, bilateral iris aplasia, left eye phthisis bulbi, pronounced delay in psycho-emotional development, lack of speech, and behavioral disorder.

Considering the ongoing pregnancy and the lack of a confirmed diagnosis, we performed NGS analysis of clinically relevant genes. Whole exome sequencing (WES) was performed using an BGISEQ-500 instrument with average on-target coverage 146× with MGIEasy Exome Capture V4 (BGI) for library preparation (Genomed Ltd., Moscow). Bioinformatic analysis was performed using an in-house software pipeline which included quality control of raw reads (FastQC tool v. 0.11.5) followed by read mapping to the hg19 human genome assembly (bwa mem v. 0.7.1), sorting of the alignments, marking duplicates (Picard Toolkit v. 2.18.14). Base recalibration and variant calling were performed with GATK3.8. Variant annotation was done using Annovar tool (v. 2018Apr16). Further filtering was performed by functional consequences and population frequencies according to the ACMG recommendations [1] as well as clinical relevance determined by Human Phenotype Ontology database [2]. The analysis lasted 42 days and revealed a novel hemizygous substitution, NM_000266.3(NDP):c.385G > T, p.(Glu129*), in the NDP gene, which was associated with Norrie disease (OMIM \#310600) inherited in X-linked recessive mode. Subsequent validation of the affected child and his mother by Sanger sequencing confirmed the identified substitution. The substitution was not registered in control cohorts in the Genome Aggregation Database (gnomAD). The identified novel NDP sequence variant c.385G > T, p.(Glu129*), forms a premature termination codon (PTC). Although the variant affects only the most C-terminal portion of the protein (129 out of 133 aminoacid residues), it eliminates the ultimate cysteine-131 residue that is involved in formation of an intermolecular disulfide bond [3]. This should lead to the disruption of a very rigid structure of Norrin homodimer. Nearby PTC forming pathogenic variants have been described p.Cys $128 *$ and p.Cys131* $[4,5]$. It was previously shown that disruption of the dimer by either cysteine-to-alanine mutations of intermolecular disulfide bonds results in a loss of Norrin function [6,7]. Norrin is an atypical Wnt ligand that can activate $\beta$-catenin signaling through its specific binding to the Frizzled4 (Fz4) receptor [8] to function as a ligand-receptor pair that controls vascular development in the retina and inner ear [6]. Pathogenic variants in the $N D P$ gene are associated with a spectrum of conditions - from milder familial exudative vitreoretinopathy to the systemic Norrie disease [9].

The clinical exome sequencing in the proband motivated amniotic fluid testing in his pregnant mother at the 17th week of gestation, which revealed after additional 5 days that the fetus was male and hemizygous for the variant. The family decided to interrupt the pregnancy after the prenatal test at the 20th week of gestation. Complications in the form of profuse uterine bleeding developed during the pregnancy termination required hysterectomy due to medical necessity.

\section{Discussion and conclusions}

Congenital vitreoretinopathy with retinal detachment is a highly heterogeneous group of disorders. Patients with genetically determined disorders such as familial exudative vitreoretinopathy, Norrie disease, or Coats disease, as well as non-hereditary retinopathy of prematurity or inflammation of the retina could have similar ocular manifestations [9]. Norrie disease is a rare X-linked recessive disorder of retinal blood vessel development. According to Orphanet database, $\sim 400$ cases have been described to date [10]. They are characterized by congenital vitreoretinopathy, avascularity of the peripheral retina and its secondary neovascularization, fibrosis, traction and retinal detachment, and blindness, which in about $25-50 \%$ of the cases, is accompanied by progressive mental retardation and/or sensorineural deafness $[11,12]$. In addition, some patients have more complex phenotypes, including growth failure and seizure. Radiological examination of some patients with Norrie disease has demonstrated brain and cerebellar atrophy [13].

The cellular basis for Norrie disease is an insufficiency of Frizzled signaling, and more specifically the Frizzled-4 ligand Norrin. Norrin functions as an activator of the canonical $\mathrm{Wnt} / \beta$-catenin signaling pathway in capillary endothelial cells in the retina and in other structures $[12,14]$. Norrin is engaged in Müller glia in the retina, in stria vascularis and a capillary plexus of cochlea, in forebrain and midbrain astrocytes, and in cerebellum Bergman glia. Norrin is also required for blood-brain barrier integrity and maintenance [15]. Thus, Norrin can have developmental and homeostatic functions beyond the retina [16].

Nucleotide sequence variants in the NDP gene are associated with several congenital retinal pathologies with or without systemic involvement. To date, 167 mutations in the NDP gene have been registered in the Human Gene Mutation Database (HGMD) - among these 
129 are associated with Norrie disease phenotype, 20 with familial exudative vitreoretinopathy, and 7 with retinopathy of prematurity. Most pathogenic variants of the NDP sequence $(n=100)$ are nonsense or missense mutations, and $80 \%$ are associated with Norrie disease [17].

In this study, we identified the pathogenic variant NM_000266.3(NDP):c.385G > T that introduces a PTC in amino-acid position 129 of Norrin. Molecular analysis allowed diagnosing Norrie disease in the patient. Severe ophthalmic phenotype with marked systemic involvement is believed to be linked to the absence of the ultimate cysteine, which forms the dimeric structure of mature Norrin and is in accordance with previous observations [18]. We suppose that in the case of earlier diagnosis, the family could have had much greater opportunity to give a healthy birth avoiding lifethreatening complications, as well as averting the psychologic tragedy in the family.

Clinical polymorphism and variable expressivity of hereditary ophthalmic pathology severely complicates the establishment of an exact diagnosis and make diagnosis time- and cost-consuming. NGS appears to be the method-of-choice in complicated cases, which could substantially hasten the establishment of a diagnosis and genetic risk estimation. This is much more important in case of extremely rare diseases that are not well-known to physicians and ophthalmologists.

\section{Abbreviations \\ ACMG: American College of Medical Genetics and Genomics; HGMD: Human Gene Mutation Database; mmHg: millimetre of mercury; NGS: Next- generation sequencing; OD (oculus dextrus): The right eye; OMIM: Online Mendelian Inheritance in Man; OS (oculus sinister): The left eye; PTC: Premature termination codon; RCMG: Research Centre for Medical Genetics; WES: Whole exome sequencing}

\section{Acknowledgements}

We thank Dr. Richard H. Lozier for interest in our work and useful assistance.

\section{About this supplement}

This article has been published as part of BMC Medical Genetics Volume 21 Supplement 1, 2020: Selected Topics in "Systems Biology and Bioinformatics" 2019: medical genetics. The full contents of the supplement are available online at https://bmcmedgenet.biomedcentral.com/articles/supplements/volume-21supplement-1.

\section{Authors' contributions}

AVM analyzed and interpreted the patient's NGS data, performed molecular genetic experiments, analyzed and interpreted the patient data, and wrote the manuscript. WK and MFS performed ophthalmic examination. SAR and IAM performed clinical examination and genetic counseling. TAV contributed to the analysis of the patient data and preparation of the manuscript. OAS and NNV performed prenatal diagnosis. SIK and RAZ designed the study and helped supervise the project. All authors read and approved the final manuscript.

\section{Funding}

Publication of this article was funded by the Russian Foundation for Basic Research (RFBR grant № 19-015-00122) and the state assignment of the Ministry of Science and Higher Education of the Russian Federation. The funders had no role in the design of the study; in the collection, analyses, or interpretation of data; in the writing of the manuscript, or in the decision to publish the results.

\section{Availability of data and materials}

The datasets used and/or analyzed during the current study are available from the corresponding author on reasonable request.

\section{Ethics approval and consent to participate}

The clinical and molecular genetic study was performed in accordance with the Declaration of Helsinki and was approved by the Institutional Review Board of the Federal State Budgetary Institution "Research Centre for Medical Genetics," Moscow, Russia, with written informed consent obtained from each participant and/or their legal representative as appropriate.

\section{Consent for publication}

Consent for publication was obtained from the legal guardian of the patient.

\section{Competing interests}

The authors declare that they have no competing interests.

\section{Author details}

'Laboratory of Genetic Epidemiology, Research Centre for Medical Genetics, Moscow, Russian Federation. ${ }^{2}$ S. Fyodorov Eye Microsurgery Federal State Institution, Moscow, Russian Federation. ${ }^{3}$ N.A. Semashko National Research Institute of Public Health, Moscow, Russian Federation.

Published: 22 October 2020

References

1. Richards S, Aziz N, Bale S, et al. Standards and guidelines for the interpretation of sequence variants: a joint consensus recommendation of the American College of Medical Genetics and Genomics and the Association for Molecular Pathology. Genet Med. 2015;17(5):405-24.

2. Köhler S, Carmody L, Vasilevsky N, et al. Expansion of the human phenotype ontology (HPO) knowledge base and resources. Nucleic Acids Res. 2019; 47(D1):D1018-27.

3. Chang TH, Hsieh FL, Zebisch M, et al. Structure and functional properties of Norrin mimic Wnt for signalling with Frizzled4, Lrp5/6, and proteoglycan. Elife. 2015:4:e6554.

4. Schuback DE, Chen ZY, Craig IW, et al. Mutations in the Norrie disease gene. Hum Mutat. 1995:5(4):285-92.

5. Salvo J, Lyubasyuk V, Xu M, et al. Next-generation sequencing and novel variant determination in a cohort of 92 familial exudative vitreoretinopathy patients. Invest Ophthalmol Vis Sci. 2015;56(3):1937-46.

6. Smallwood PM, Williams J, Xu Q, et al. Mutational analysis of NorrinFrizzled4 recognition. J Biol Chem. 2007;282(6):4057-68.

7. Ke J, Harikumar KG, Erice C, et al. Structure and function of Norrin in assembly and activation of a frizzled 4-Lrp5/6 complex. Genes Dev. 2013; 27(21):2305-19.

8. Xu Q, Wang Y, Dabdoub A, et al. Vascular development in the retina and inner ear: control by Norrin and Frizzled-4, a high-affinity ligand-receptor pair. Cell. 2004;116(6):883-95.

9. Dickinson JL, Sale MM, Passmore A, et al. Mutations in the NDP gene: contribution to Norrie disease, familial exudative vitreoretinopathy and retinopathy of prematurity. Clin Exp Ophthalmol. 2006;34(7):682-8.

10. Prevalence of rare diseases: Bibliographic data - January 2019. 2019 Contract No.: Number 1 : Diseases listed in alphabetical order. https://www.orpha. net/orphacom/cahiers/docs/GB/Prevalence_of_rare_diseases_by_ alphabetical_list.pdf.

11. Kondo H. Complex genetics of familial exudative vitreoretinopathy and related pediatric retinal detachments. Taiwan J Ophthalmol. 2015:5(2):56-62.

12. Ohlmann A, Tamm ER. Norrin: molecular and functional properties of an angiogenic and neuroprotective growth factor. Prog Retin Eye Res. 2012; 31(3):243-57.

13. Rodriguez-Munoz A, Garcia-Garcia G, Menor F, et al. The importance of biochemical and genetic findings in the diagnosis of atypical Norrie disease. Clin Chem Lab Med. 2018;56(2):229-35.

14. Bang I, Kim HR, Beaven $\mathrm{AH}$, et al. Biophysical and functional characterization of Norrin signaling through Frizzled4. Proc Natl Acad Sci U S A. 2018; 115(35):8787-92.

15. Zhou Y, Wang Y, Tischfield M, et al. Canonical WNT signaling components in vascular development and barrier formation. J Clin Invest. 2014:124(9): 3825-46. 
16. Ye X, Smallwood P, Nathans J. Expression of the Norrie disease gene (Ndp) in developing and adult mouse eye, ear, and brain. Gene Expr Patterns. 2011;11(1-2):151-5.

17. Musada GR, Jalali S, Hussain A, et al. Mutation spectrum of the Norrie disease pseudoglioma (NDP) gene in Indian patients with FEVR. Mol Vis. 2016;22:491-502

18. Wu WC, Drenser K, Trese M, et al. Retinal phenotype-genotype correlation of pediatric patients expressing mutations in the Norrie disease gene. Arch Ophthalmol. 2007;125(2):225-30.

\section{Publisher's Note}

Springer Nature remains neutral with regard to jurisdictional claims in published maps and institutional affiliations.

Ready to submit your research? Choose BMC and benefit from:

- fast, convenient online submission

- thorough peer review by experienced researchers in your field

- rapid publication on acceptance

- support for research data, including large and complex data types

- gold Open Access which fosters wider collaboration and increased citations

- maximum visibility for your research: over $100 \mathrm{M}$ website views per year

At BMC, research is always in progress.

Learn more biomedcentral.com/submissions 